\title{
QUANDO VIVER É CAMPESINAR, O CAMPO É DE POSSIBILIDADES ${ }^{1}$
}

\section{CUANDO VIVIR ES CAMPESINAR, EL CAMPO ES DE POSIBILIDADES}

\author{
Gabriel Dayer Lopes de Barros Moreira \\ Programa de Pós-Graduação em Desenvolvimento, Agricultura e Sociedade - CPDA/UFRRJ \\ Bolsista CNPq \\ gabriel_dayer@yahoo.com.br
}

\begin{abstract}
Resumo
Este artigo aporta elementos e reflexões em torno da questão agrícola-agrária e da possibilidade camponesa no Brasil. O recente retorno do uso do conceito campesinato pelos movimentos sociais e pela academia revela, ao mesmo tempo, seu vigor teóricopolítico e a complexidade de seu uso frente à heterogeneidade sociocultural, política, ecológica e econômica presente no campo brasileiro. Por isso, no que tange aos campesinatos, edificações teóricas mais "abertas", balizadas por uma perspectiva multiescalar e em conexão com as experiências vivenciadas pelos sujeitos, possibilitam leituras mais próximas das realidades sociais. Vistos mais de perto e de maneira multidimensional, a "terra é mais que terra" e os modos de resistências se confundem com os mundos de existência. Buscar conexões entre autores/as de diversos campos do saber, rompendo com rígidos limites disciplinares, apresenta-se como um desafio para os estudos rurais contemporâneos. Este texto é um exercício nesse sentido.
\end{abstract}

Palavras-chave: Campesinato. Contra hegemonia. Questão agrária. Resistência. Território.

\section{Resumen}

Este artículo aporta elementos y reflexiones sobre la cuestión agrícola-agraria y sobre la posibilidad campesina en Brasil. El reciente retorno del uso del concepto de campesinado por parte de los movimientos sociales y por la academia revela, al mismo tiempo, su vigor teórico-político y la complejidad de su uso frente a la heterogeneidad sociocultural, política, ecológica y económica en el campo brasilero. Por este motivo, en lo que se refiere a los campesinados, las construcciones teóricas más "abiertas", señaladas por una perspectiva multiescala y en conexión con las experiencias vividas por los sujetos sociales, permiten aproximaciones más coherentes con las realidades. Desde una perspectiva más cercana y multidimensional, la "tierra es más que tierra" y las formas de resistencias se confunden con los mundos de existencia. La búsqueda por conexiones entre autores/as de diversos campos del saber, rompiendo con los rígidos límites disciplinarios, se presenta como un desafío para los estudios rurales contemporáneos. Este texto es un ejercicio en este sentido.

Palabras claves: Campesinado. Contrahegemonía. Cuestión agraria. Resistencia. Territorio.

CAMPO-TERRITÓRIO: revista de geografia agrária, v. 11, n. 22, p. 208-221, abr., 2016 


\section{Introdução}

O Campesinato brasileiro: uma história de resistência, afirma o título de um artigo recente de Maria de Nazareth Baudel Wanderley (2015). Além da constatação primeira, a anotação sugere sua contraface: a permanência de assimétricas relações sociais e de poder no campo brasileiro. Do sistema de plantations à sociedade do agronegócio (HEREDIA et al., 2010), corridos mais de "cinco séculos de latifúndios" e da chegada da propagada modernidade, novas-antigas questões e as antigas-novas tensões se apresentam. Talvez a expressão agronegócio latifundiário, tão evidente quanto velada, seja a que melhor sintetize o grande desafio agrário-agrícola brasileiro contemporâneo.

É verde o cenário em que, como reação à conjuntura desafiadora, ressurgem estudos e lutas sociais que têm o campesinato como referência conceitual e política. Isto porque, mesmo paulatinamente apropriada pela economia de mercado, a questão ecológica tem conseguido expor à sociedade os modos predatórios e violentos de exploração dos ambientes e de suas gentes. Ao defender a atualidade do uso e a densidade histórica do conceito de campesinato, Marta Inês Medeiros Marques (2012) sugere que ele "remete a um passado de lutas no campo e ao futuro como possibilidade". Afirma a autora:

\footnotetext{
Enquanto o campo brasileiro tiver a marca da extrema desigualdade social e a figura do latifúndio se mantiver no centro do poder político e econômico esteja ele associado ou não ao capital industrial e financeiro -, o campesinato permanece como conceito-chave para decifrar os processos sociais e políticos que ocorrem neste espaço e suas contradições (MARQUES, 2012, p.58).
}

Entretanto, a complexidade das realidades, das identidades e dos conflitos sociais torna igualmente complexo o exercício teórico-político de delimitação conceitual de campesinato. Considerando-se que as identidades sociais são dinâmicas, relacionais e contrastivas (HALL, 2014) e que a história é movimento, um determinado conceito pode rapidamente perder sua capacidade explicativa frente às dinâmicas sociais. Não se pode, ademais, abandonar de vista a impossibilidade teórica de uma leitura da totalidade de uma realidade. "A realidade extrapola o conceito", nos diz Frei Betto (1985) lembrando-se de Tomás de Aquino. Na verdade, sob o ponto de vista epistemológico, o próprio conhecimento científico rogou para si um reino totalitário na medida em que demarcou claramente os limites entre o que seria o conhecimento 
científico e o que não seria; mais que isso, conquistou o privilégio de definir o que é conhecimento válido (SANTOS et al., 2004), invisibilizando grande parte do rico espectro epistemológico humano. Encontram-se neste limbo as sabedorias e a memória biocultural dos povos camponeses e indígenas latino-americanos (TOLEDO; BARRERA-BASSOLS, 2008).

Notadamente se tratando do(s) campesinato(s) - em suas diversas possibilidades, circunstâncias e realidades - edificações teóricas mais "abertas" e balizadas por uma perspectiva multidimensional pode ser um caminho interessante em termos analíticos. Em nosso entendimento, situa-se nesse horizonte a abordagem de Wanderley (2015), na qual o campesinato é caracterizado como "uma forma de viver e trabalhar no campo que, mais do que uma simples forma de produzir, corresponde a um modo de vida e uma cultura", onde as especificidades das situações concretas de reprodução explicitam conteúdos sociais particulares.

Mirar situações concretas "de perto e de dentro" (MAGNANI, 2002) também nos ajuda a perceber traços comuns e próprios dos diversos povos do campo brasileiro. No que tange às interrelações que envolvem famílias camponesas do Cerrado e seus ambientes lembramos da observação de Ricardo Ferreira Ribeiro (2006) ao estudar sistemas agrícolas nos sertões mineiros:

É muito difícil se conseguir uma classificação de ambientes de moradores do Cerrado, pois, em primeiro lugar, cada região tem uma divisão própria, fruto da sua paisagem específica, mas também da cultura local. Por outro lado, há certas particularidades na descrição de cada ambiente que podem apresentar diferenças até entre vizinhos (RIBEIRO, 2006, p.97).

Os caminhos trilhados por Wanderley (2015) sugerem uma correlação entre as particularidades do campesinato brasileiro e suas estratégias de resistência frente ao modo que historicamente se estruturou a atividade agrícola no país. Ou seja, a capacidade de se criar espaços para formas de agricultura de base familiar/comunitária nos "interstícios internos e externos dos latifúndios". A autora lembra que as formas precárias (sem titulação jurídica) de acesso a terra é um traço do campesinato nacional e que há uma diversidade de modalidades de acesso. Tais modalidades refletiriam situações de maior ou menor subordinação (ou autonomia) familiar².

Tendo em vista a diversidade de expressões dos modos de ser/viver, de resistir e de praticar agricultura no Brasil, este artigo traz alguns apontamentos e reflexões 
interdisciplinares relativos à condição/possibilidade camponesa e à questão agrícolaagrária na atualidade.

\section{Quando a terra-natureza é mercadoria}

Ao analisar os dados dos conflitos fundiários nos últimos 30 anos no Brasil, Leonilde Sérvolo de Medeiros (2014) ressalta a ausência de acesso à terra como questão central na permanência do padrão de conflitualidade no campo. Para a autora, ainda que ao longo dos anos as disputas tenham se revestido de diversas maneiras, sua raiz está na transformação da terra em mercadoria.

A leitura de Polanyi (2011) contribui na compreensão da associação entre a apropriação capitalista da terra e estabelecimento da economia de mercado. Essa é uma característica fundamental da Revolução Industrial, por sua vez, um dos pilares da modernidade capitalista. No campo ideológico, essa economia foi justificada pela idéia de um sistema autorregulável de mercados, fabulação dos economistas liberais do século XIX. Portador de uma suposta "propensão à barganha, à permuta e a troca", o Homo economicus de Adam Smith seria a representação máxima desse constructo (POLANYI, 2011).

Polanyi afirma que uma economia de mercado só pode existir em uma sociedade de mercado. Assim, a grande transformação envolve necessariamente a transformação/desagregação do tecido social pré-existente. No que tange à economia, relaciona-se com a transformação de mercados reguláveis, sociocultural e localmente referenciados, em mercados ditos autorreguláveis (à mercê de determinações exógenas).

[...] até a nossa época os mercados nada mais eram do que acessórios da vida econômica. Como regra, o sistema econômico era absorvido pelo sistema social e, qualquer que fosse o princípio de comportamento predominante na economia, a presença do padrão de mercado sempre era compatível com ele (POLANYI, 2011, p.73).

O autor revela ainda que uma economia de mercado deve ser capaz de compreender todos os componentes da indústria. Inclui-se aí terra (natureza), além do trabalho (ser humano) e do dinheiro. Seriam tais componentes, no entanto, mercadorias fictícias $^{3}$, isto é, inseridas nos mecanismos de mercado sem serem mercadorias de fato (objetos produzidos para a venda). Incluir a terra-natureza, o trabalho e o dinheiro 
nesses mecanismos seria determinante para "subordinar a substância da própria sociedade às leis do mercado" (POLANYI, 2011, p.77).

Como demonstrou Marx (1996) no capítulo XXIV de O Capital, a expropriação territorial, a separação do produtor direto de seus meios de vida, é o "pecado original" das sociedades capitalistas. No Brasil, a transformação da terra-natureza em mercadoria, a expropriação territorial e a interdição dos acessos dos/as camponeses/as à terra compõem um mesmo enredo. Promulgada em 1850, a Lei de Terras foi o marco jurídico que assegurou antigos privilégios, implantou a propriedade privada da terra e restringiu seu acesso. A partir de 1888, com a abolição da escravatura, ocorre também a transformação do trabalho em mercadoria. As transformações desse momento histórico são sintetizadas por José de Souza Martins (2013): "Enquanto o trabalho era escravo, a terra era livre; quando o trabalho ficou livre, a terra vira escrava".

Tempos após, com a industrialização, o "desenvolvimento" e o crescimento econômico, ocorre uma intensificação dos processos de avanço capitalista no campo. Tomado pelo ímpeto desenvolvimentista, o governo JK favoreceu a entrada de capitais estrangeiros e subsidiou fortemente investimentos industriais. Francisco Julião, dialogando sobre as origens e causas das Ligas Camponesas, retrata a situação do campesinato alemão dos séculos XV e XVI para comentar o momento brasileiro:

\footnotetext{
A concentração do capital e do trabalho escravo (na Alemanha) favoreceram a construção de obras suntuosas, castelos, igrejas e monumentos tão altos como as montanhas para refletir o poderio das classes dominantes. Tudo isso argamassado pelo sangue e pelo suor dos camponeses, como se fez em Brasília, cujos edifícios foram alicerçados, no sacrifício de centenas de milhares de camponeses, no quinquênio Juscelino Kubitschek, que não teve uma palavra de esperança sequer para o campesinato, mas abriu, como nenhum outro, as portas do país ao capital estrangeiro monopolista e espoliador de nossas riquezas (JULIÃO, 1962, p.14).
}

Com o golpe de 1964, o Brasil intensifica e impõe a modernização no campo brasileiro. A militarização da questão agrária, a expropriação de camponeses e aumento da exploração dos/as trabalhadores/as foi, segundo Maria Aparecida Moraes Silva (2004), o tripé utilizado pelo projeto modernizador da agricultura para alcançar seus objetivos. A pesquisadora destaca que no processo de expropriação a violência era cometida tanto pelos latifundiários quanto pelas grandes empresas nacionais/internacionais ligadas ao capital financeiro e beneficiadas por incentivos fiscais para compra de terras a preços irrisórios.

CAMPO-TERRITÓRIO: revista de geografia agrária, v. 11, n. 22, p. 208-221, abr., 2016 
O estabelecimento de grandes latifúndios florestais no Vale do Jequitinhonha MG na década de 1970 é um exemplo do movimento das engrenagens do Moinho Satânico, aludido por Polanyi. O cenário monocultural da paisagem da microrregião do alto Jequitinhonha, tomada pelas chamadas florestas plantadas, revelam feridas de uma história recorrente de expropriação territorial, expulsão de famílias camponesas e devastação ecológica. "A chegada do estranho nos Grandes Sertões e Veredas", destaca Moraes Silva (1999), remete a traços comuns do sistema clássico inglês da acumulação primitiva estudado por Marx. A expropriação do campesinato, neste caso, não ocorreu totalmente por meio da violência aberta, foi sim, intermediada por uma violência velada e legal monopolizada pelo Estado (MORAES SILVA, 1999). Como assinalam Fávero e Monteiro (2014),

[...] na esteira desenvolvimentista dos governos militares, foram financiados
grandes projetos de monocultivos de eucalipto nas Chapadas com vistas a
atender a crescente demanda de carvão vegetal do polo siderúrgico de Minas
Gerais. Extensas áreas de Cerrado foram substituídas por monocultivos de
eucalipto, ao ponto de a região ser considerada, atualmente, o maior maciço
de eucalipto da América Latina. Empresas receberam terras públicas em
regime de comodato; proprietários locais foram pressionados a vender suas
terras; e, sobretudo, posseiros foram expulsos e/ou empurrados para os vales
e grotas. As Chapadas foram consideradas grandes vazios demográficos,
ignorando as formas de ocupação e uso do território pelas comunidades
camponesas e, levando à expropriação das famílias (MONTEIRO; FÁVERO,
2014, p.11)

Este é apenas um caso, dentre inúmeros, capaz de ilustrar como as profundas alterações nas relações de produção advindas da ofensiva modernizante pouco alterou as estruturas fundiárias no país. Pelo contrário. A associação entre o capital industrial e os latifundiários enrijeceu ainda mais as desigualdades sociais e o processo violento contra os territórios camponeses e indígenas.

\begin{abstract}
A chamada modernização da agricultura não vai atuar no sentido da transformação de latifundiários em capitalistas, mas ao contrário, transformou os capitalistas industriais e urbanos - sobretudo do centro sul do país - em proprietários de terras, em latifundiários. [...]. Desta forma, os capitalistas urbanos tornam-se os maiores proprietários de terra no Brasil, possuindo áreas com dimensões nunca registradas na história da humanidade (OLIVEIRA, 2001, p.186).
\end{abstract}

A partir dos anos 1990, com o avanço da globalização neoliberal e a emergência do "agronegócio" e da "economia verde" no Brasil, as transformações no mundo rural reafirmaram antigos e geraram novos impactos, como aqueles associados ao 
desenvolvimento da engenharia genética e ao monopólio comercial por corporações transnacionais. É tempo de devastação contínua e também de incorporação dos “constrangimentos ambientais" à lógica capitalista.

Emergem igualmente novas interpretações teóricas. David Harvey (2005), seguindo caminhos trilhados por Rosa Luxemburgo, propõe o conceito de acumulação por espoliação (ou despossessão) e atualiza a "acumulação primitiva" de Marx. O autor enfatiza que as características mencionadas por Marx continuam presentes e podem ser evidenciadas na expulsão de populações camponesas. Incidem, contudo, mecanismos novos e mais aprimorados ("novos cercamentos") no âmbito da reprodução capitalista no período neoliberal.

\begin{abstract}
Foram criados mecanismos inteiramente novos de acumulação por espoliação. A ênfase nos direitos de propriedade intelectual nas negociações da OMC (o chamado acordo TRIPS) aponta para maneiras pelas quais o patenteamento e o licenciamento de material genético, do plasma de sementes e de todo tipo de outros produtos podem ser usados agora contra populações inteiras cujas práticas tiveram um papel vital no desenvolvimento desses materiais. [...]. A transformação em mercadoria de formas culturais, históricas e da criatividade intelectual envolve espoliação em larga escala (HARVEY, 2005, p.123).
\end{abstract}

A base da acumulação por espoliação estaria vinculada, segundo Harvey, às crises de sobreacumulação do sistema capitalista e sua capacidade de "criar seu próprio outro" para se alimentar. A crise de 1973 seria o marco para o domínio do capital financeiro - altamente especulativo e predatório - e a privatização um dos caminhos possíveis para a liberação de ativos e resposta à crise: "O que a acumulação por espoliação faz é liberar um conjunto de ativos (incluindo a força de trabalho) a custo muito baixo (e, em alguns casos, zero). O capital sobreacumulado pode apossar-se desses ativos e dar-lhes imediatamente um uso lucrativo" (HARVEY, 2005, p.124).

Se, ao tratar do papel do Estado no nascimento do capitalismo, Marx notou que “A violência é a parteira de toda velha sociedade que está prenhe de uma nova. (E que) ela mesma é uma potência econômica" (MARX, 1996, p.370); em tempos neoliberais, Harvey percebe que "o cordão umbilical que une a acumulação por espoliação $e$ reprodução expandida é o que lhes dão o capital financeiro e as instituições de crédito, como sempre com o apoio dos poderes do Estado" (2005, p.126).

CAMPO-TERRITÓRIO: revista de geografia agrária, v. 11, n. 22, p. 208-221, abr., 2016 


\section{Quando vida é resistência (ou Quando a terra é mais que terra)}

O conceito de acumulação via espoliação de Harvey traz elementos que colaboram para uma interpretação multifacetada dos processos sociais e econômicos relacionados à pilhagem moderna dos territórios camponeses. Com o processo de globalização neoliberal e sua irradiação sobre múltiplos aspectos da vida em comunidade nunca foi tão evidente, como lembra Ianni (2009), que toda opressão econômica é também sociocultural e política.

Em situações onde os contornos de uma construção hegemônica se desenham necessariamente sobre as linhas gerais dos modos de ser e viver do(s) campesinato(s), a resistência e a vida se entrelaçam num mesmo enredo contra-hegemônico. Desafiam também os próprios grupos sociais reinventarem suas lutas frente à lógica envolvente. Vale rememorar que o movimento seringueiro do Acre empatou ${ }^{4}$ e tensionou o Estado na construção de uma proposta inédita e diferenciada de garantia de direitos territoriais, em um momento histórico de ameaça e expropriação de territórios pelo avanço do capital: a chegada dos "paulistas" na Amazônia. As Reservas Extrativistas nascem dos entrelaços entre a vida na floresta, a interação com povos indígenas e as opções políticas do movimento dos seringueiros.

Sabe-se que os "povos da floresta" têm raízes nordestinas e que adotaram o genérico termo "paulista" para representar a ameaça dos grandes pecuaristas e especuladores de toda a região Centro Sul que, violentamente e autorizados pelo Estado, invadiam seus lugares de vida. É curioso notar, de acordo com a pesquisa de Woortmann (2009), que "São Paulo" não corresponde necessariamente a uma localização espacial para os sitiantes sergipanos migrantes. Conta-nos o pesquisador que "[...] o filho de um informante que havia migrado para "São Paulo" encontrava-se, de fato, em Rondônia, outro jovem no Paraná, e um terceiro, no Paraguai”. Assim, aponta Woortmann: "São Paulo não é uma localização territorial precisa, mas uma categoria classificatória que se opõe ao "Norte", na medida em que este é o lugar da escassez, e o primeiro é o lugar da riqueza". Nesse complexo de representações/significações territoriais é possível perceber aspectos do Mundo e da percepção do Outro desde a ótica camponesa.

Carlos Walter Porto-Gonçalves, por seu turno, nos leva a refletir sobre as amplitudes espaço-temporais das lutas camponesas ao lembrar o processo iniciado na 
década de 1970 na Amazônia ressoa nas lutas contemporâneas por retomada de territórios em outros biomas, "como se vê nas reivindicações de amplas áreas como Reservas Extrativistas que reinventam, nos Cerrados e contra o agronegócio, a tese de Chico Mendes de que 'não há defesa da floresta sem os povos da floresta'" (PORTOGONÇALVES, 2014, p.95). Criada em 2014, a Reserva de Desenvolvimento Sustentável Nascentes Geraizeiras - localizada nos municípios de Montezuma, Rio Pardo de Minas e Vargem Grande do Rio Pardo - é um exemplo de Unidade de Conservação de Uso Sustentável conquistada após 12 anos de resistências e lutas do povo Geraizeiro no Norte de Minas Gerais.

É importante sublinhar que as lutas camponesas possuem um amplo lastro, se estendendo desde ações coletivas e diretas de enfrentamento (como a ocupação de latifúndios ou empresas do agronegócio) até resistências a nível familiar/comunitário (como uma família camponesa que se recusa a utilizar sementes comerciais transgênicas e conserva suas variedades crioulas). Comporta também distintas escalas: de articulações locais ou regionais até redes mundiais de movimentos sociais, como a Via Campesina. Mas está também, e, sobretudo, naquilo que não se vê. Em valores culturais, nas relações sociais e políticas, nas autonomias comunitárias (ainda que relativas). Relações estas muitas vezes referenciadas no "mistério" e no "milagre" que nos conta e inspira João Guimarães Rosa: "Tudo, aliás, é a ponta de um mistério. Inclusive os fatos. Ou a ausência deles. Duvida? Quando nada acontece, há um milagre que não estamos vendo". No que tange a luta pela terra, retomamos a utopia camponesa de Ianni (2009):

\footnotetext{
Mesmo quando essa (a terra) é a reivindicação principal, ele compreende outros ingredientes. A cultura, a religião, a língua ou dialeto, a etnia ou raça entram na formação e no desenvolvimento das suas reivindicações e lutas. Mais que isso, pode-se dizer que a luta pela terra é sempre, ao mesmo tempo, uma luta pela preservação, conquista ou reconquista de um modo de vida e trabalho. Todo um conjunto de valores culturais entra em linha de conta, como componentes de um modo de ser e viver (IANNI, 2009, P.142).
}

Ao socializar a convicção de um sitiante sergipano de que Com Parente Não se Neguceia, Woortmann (1990) sugere a campesinidade ${ }^{5}$ como expressão da ética camponesa e de uma ordem moral presente "em muitos lugares e em muitos tempos", "um modo de ser não local, mas específico, distinto quando contrastado à ordem da modernidade". A terra não é percebida como fator de produção, mas como expressão de 
uma moralidade, tem valor ético: “[...] o significado da terra é o significado do trabalho e o trabalho o significado da família, como o é, igualmente, a terra enquanto patrimônio. Mais que objeto de trabalho a terra é o espaço da família" (WOORTMANN, 1990, p.43). Em contraste com o Homo economicus de Adam Smith, terra, trabalho e família constituem categoriais interdependentes de ordenamento do mundo do Homo moralis de Woortmann e não podem ser levadas em consideração separadamente.

Sob o ponto de vista econômico, Alexander Chayanov (2014) oferece contribuições ao substituir a lente e olhar para os tipos não capitalistas de vida econômica. $\mathrm{O}$ autor discute as limitações de se aplicar a teoria econômica da sociedade capitalista no entendimento da lógica camponesa (forma de exploração familiar sem assalariamento). Os princípios e as categorias fundamentais dessa teoria (preço, capital, salário, juro, renda), lembra, estão baseados no trabalho assalariado e visam a maximização dos lucros. Tais categorias formariam um todo interdependente e a retirada de qualquer alguma delas provocariam perturbações em todo edifício teórico (CHAYANOV, 2014, p.103). Assim, por exemplo, a ausência de assalariamento, como no caso da agricultura camponesa, inviabilizaria a presença do cálculo de lucro líquido e da análise econômica sob a ótica capitalista.

Contrariando o que se espera partindo-se da racionalidade econômica moderna, a intepretação chayanoviana sugere que a maximização dos lucros não seria o fator determinante que moveria a intensidade do trabalho agrícola camponês. Tirando partido do mercado e das condições naturais, a família camponesa buscaria um equilíbrio interno, carregado de subjetividades, visando o máximo de bem estar. Desde uma perspectiva histórica, Chayanov indica ser somente com o aumento da troca e circulação monetária que as quantidades se tornam independentes de aspectos qualitativos e o preço assume papel mais importante (2014, p.104).

Frente à face perversa (ou neoliberal) da globalização ${ }^{6}$ e da tentativa de imposição do pensamento único, a leitura de Chayanov contribui na afirmação de que, assim como a diversidade agroecossistêmica ou de identidades tecidas nas relações (e lutas) sociais, há uma pluralidade de ordens econômicas no campo. Mais ou menos conectadas e influenciadas pela mundialização capitalista, tais ordens continuam presentes, diferenciadas e vivas. Apresentam-se, por exemplo, quando um/a camponês/a

CAMPO-TERRITÓRIO: revista de geografia agrária, v. 11, n. 22, p. 208-221, abr., 2016 
feirante do Vale do Jequitinhonha se recusa a adotar pequenas balanças eletrônicas e afirma seu sistema socialmente situado e "impreciso" de medidas.

\section{Considerações finais}

Em linhas gerais, sublinhamos que ao lado da questão agrária-agrícola, associada aos problemas advindos do avanço da lógica da economia de mercado no campo e ao modelo agroexportador de commodities, gravitam outras questões. Entre elas, a questão epistemológica (ou da violência epistêmica) e a questão camponesa.

Em tempos de globalização neoliberal, onde se complexificam as formas de imposição ideológica e as violências contra os povos do campo, modos de resistir se aproximam dos mundos de existência. Neste cenário, (re) nascem identidades, desafios, motivações e lutas. São valores e possibilidades contra-hegemônicas, próprias das horizontalidades e contiguidades desses espaços de vida, que vislumbram outros sentidos para a verticalidade globalizante. Como acreditava Milton Santos, por uma outra globalização.

Enfim, são diversas e multiterritoriais as lutas, porque também os são os lugaresmundos camponeses. Contrariando teses que ora logravam o seu fim, ora reduziam-na pelo viés economicista, das plantations ao agronegócio segue a marcha do(s) campesinato(s). Com ela, o potencial transformador da utopia camponesa.

\footnotetext{
Notas

${ }^{1}$ A elaboração deste artigo foi motivada por leituras e debates realizados na disciplina "Questão Agrária: uma perspectiva histórica" do CPDA/UFRRJ ministrada pela professora Débora Lerrer.

${ }^{2}$ Cabe acrescentar que, segundo Wanderley (2015), em situações de uma economia camponesa mais "liberta" a tensão subordinação/autonomia pode se deslocar para o âmbito da comercialização dos produtos.

${ }^{3}$ De acordo com Polanyi (2011, p.77): "Trabalho é apenas um outro nome para atividade humana que acompanha a própria vida que, por sua vez, não é produzida para venda mas por razões inteiramente diversas, e essa atividade não pode ser destacada do resto da vida, não pode ser armazenada ou mobilizada. Terra é apenas outro nome para a natureza, que não é produzida pelo homem. Finalmente, o dinheiro é apenas um símbolo do poder de compra e, como regra, ele não é produzido mas adquire vida através do mecanismo dos bancos e das finanças estatais."

${ }^{4}$ Osmarino Amâncio (2004), líder sindical e seringueiro de Xapuri - AC relata o surgimento dos empates: "Em 75, a gente fundou o primeiro sindicato, lá na nossa região. Começamos esse processo de discussão da chegada do pessoal daqui pra lá, em 73, com as Comunidades Eclesiais de Base. Então, a gente começou, mas as Comunidades tinham um limite pra atuar e a gente precisava de uma coisa mais audaciosa. Assim, vieram os sindicatos, e foi com os sindicatos que os seringueiros (no mês de março a abril) chegaram para o Wilson Pinheiro, para o Chico Mendes, para todo mundo e disseram: "Olha, o pessoal já chegou lá no seringal, de carro, e vão derrubar todo o seringal e vão expulsar mais de
}

CAMPO-TERRITÓRIO: revista de geografia agrária, v. 11, n. 22, p. 208-221, abr., 2016 
cinquenta, setenta famílias". E ai o Wilson Pinheiro, o Elias Roseano chamaram os companheiros para uma reunião e disseram: "Nos vamos ter que evitar, sabe, nós não derrubamos a floresta, nós não vamos permitir que ela caia. Já que a gente não derruba ela, a gente também não vamos deixar eles derrubar." E ai eles disseram: "Vamos empatá, né?". E ai surgiu a palavra empate, que no esporte é um a um, dois a dois, zero a zero, ninguém ganha, ninguém perde. Mas, para nós, o empate significava uma vitória; pois, como a floresta ficava em pé, pra gente era a garantia da nossa sobrevivência."

5 "Prefiro então falar não de camponeses, mas de campesinidade, entendida como uma qualidade presente em maior ou menor grau em distintos grupos específicos. Se há uma relação entre formas históricas de produção e essa qualidade, tal relação não é, contudo, mecânica. O que tenho em vista é uma configuração modelar, mas é preciso não esquecer, sob risco de reificação, que pequenos produtores concretos não são tipos, mas sujeitos históricos e que as situações empíricas observadas, por serem históricas, são ambíguas. De fato, pode-se perceber a história como uma contínua produção e resolução de ambigüidades". (WOORTMANN, 1990, p.13).

${ }^{6}$ Milton Santos (2001) percebe o processo de globalização como fábula (como nos fazem vê-lo), como perversidade (tal como ele é) e como possibilidade (como ele pode ser).

\section{Referências}

AMÂNCIO, Osmarino. Os seringueiros do Acre e os impasses na exploração da floresta. O campo no século XXI. 1.ed. São Paulo: Editora Casa Amarela e Editora Paz e Terra, 2004.

BETTO, Frei. O que é Comunidade Eclesial de Base. 1.ed. São Paulo: Abril Cultural/Brasiliense, 1985.

CHAYANOV, Alexander V. Teoria dos sistemas econômicos não capitalistas (1924). In: CARVALHO, Horácio Martins de (Org.). Chayanov e o campesinato. 1.ed. São Paulo: Expressão Popular, 2014.

FÁVERO, Claudenir; MONTEIRO, Fernanda Testa. Disputas territoriais no Vale do Jequitinhonha: uma leitura pelas transformações nas paisagens. Agriculturas, v. 11, n. 3, 2014.

HALL, Stuart. Quem precisa de identidade?. In: SILVA, Tadeu Tomaz. (Org.).

Identidade e diferença: a perspectiva dos estudos culturais. 15. ed. Petrópolis: Vozes, 2014.

HARVEY, David. O Novo Imperialismo. 2.ed. São Paulo: Loyola, 2005

HEREDIA, Beatriz; PALMEIRA, Moacir; LEITE, Sérgio Pereira. Sociedade e economia do "agronegócio" no Brasil. Revista Brasileira de Ciências Sociais, v. 25, n. 74, p. 159-176, 2010.

IANNI, Octávio. A utopia camponesa (1986). In: WELCH, Clifford Andrew et al. Camponeses brasileiros: leituras e interpretações clássicas, v. 1, 2009.

JULIÃO, Francisco. O que são as Ligas Camponesas?. 1.ed. Rio de Janeiro, Civilização Brasileira, 1962.

CAMPO-TERRITÓRIO: revista de geografia agrária, v. 11, n. 22, p. 208-221, abr., 2016 
MAGNANI, J. G. C. De perto e de dentro: notas para uma etnografia urbana. Revista Brasileira de Ciências Sociais, v. 17, n. 49, p.11-29, 2002.

MARQUES, Marta Inês Medeiros. A atualidade do uso do conceito de camponês. Revista Nera, n. 12, p. 57-67, 2012.

MARTINS, José de Souza. O cativeiro da terra. 9. ed. São Paulo: Contexto, 2013.

MARX, Karl. Coleção Os Economistas. O Capital: crítica da economia política. São Paulo: Nova Cultural, 1996.

MEDEIROS, Leonilde Sérvolo de. Conflitos Fundiários e Violência no Campo In: Comissão Pastoral da Terra. Conflitos no campo - Brasil 2014. CPT Nacional - Brasil, 2014.

MORAES SILVA, Maria Aparecida de. A luta pela terra. Experiência e memória. São Paulo: Edunesp, 2004.

MORAES SILVA, Maria Aparecida de. Errantes do fim do século. São Paulo: Unesp, 1999.

OLIVEIRA, Ariovaldo Umbelino. A Longa marcha do Campesinato Brasileiro: movimentos sociais, conflitos e reforma agrária. Estudos Avançados. São Paulo: USP, v. 15, n. $43,2001$.

POLANYI, Karl. A Grande Transformação: as origens da nossa época. Rio de Janeiro: Campus, 2011.

PORTO-GONÇALVES, Carlos Walter. Dos Cerrados e de suas riquezas: não há defesa dos Cerrados sem os Povos dos Cerrados!. In: Comissão Pastoral da Terra. Conflitos no campo - Brasil 2014. CPT Nacional - Brasil, 2014.

RIBEIRO, Ricardo Ferreira. Sertão, Lugar Desertado: o cerrado na cultura de Minas Gerais. Autêntica, 2006.

SANTOS, Boaventura de Sousa; MENESES, Maria Paula G.; NUNES, João Arriscado. Introdução: para ampliar o cânone da ciência: a diversidade epistemológica do mundo. In: Semear outras soluções: os caminhos da biodiversidade e dos conhecimentos rivais, v. 4, 2004.

SANTOS, Milton. Por uma outra globalização: do pensamento único à consciência universal. Rio de Janeiro/São Paulo: Editora Record, 2001.

TAVARES DOS SANTOS, José Vicente. Colonos do vinho: estudo sobre a subordinação do trabalho camponês ao capital. São Paulo: Hucitec, 1978.

TOLEDO, Víctor M.; BARRERA-BASSOLS, Narciso. La Memoria Biocultural: la importância ecológica de las sabidurías tradicionales. Barcelona: Icaria Editorial, 2008.

CAMPO-TERRITÓRIO: revista de geografia agrária, v. 11, n. 22, p. 208-221, abr., 2016 
WANDERLEY, Maria de Nazareth Baudel. O campesinato brasileiro: uma história de resistência. Revista de Economia e Sociologia Rural (Impresso), v. 52, p. 25-44, 2015.

WOORTMANN, Klaas. Com parente não se neguceia: o campesinato como ordem moral. Anuário antropológico, v. 87, p. 11-73, 1990.

WOORTMANN, Klaas. Migração, família e campesinato (1990). WELCH, Clifford Andrew et al.. Camponeses brasileiros: leituras e interpretações clássicas, v. 1, 2009. 